\title{
Design and Investigation of Differential-Fed Ultra-Wideband Patch Antenna with Polarization Diversity
}

\author{
Yanfang Wang, ${ }^{1}$ Fuguo Zhu, ${ }^{2}$ and Steven $\mathrm{Gao}^{3}$ \\ ${ }^{1}$ College of Computer and Information, Hohai University, Nanjing 211100, China \\ ${ }^{2}$ Science and Technology on Antenna and Microwave Laboratory, Nanjing 210039, China \\ ${ }^{3}$ School of Engineering and Digital Arts, University of Kent, Canterbury CT2 7NT, UK \\ Correspondence should be addressed to Fuguo Zhu; zhu.fuguo@hotmail.com \\ Received 24 July 2016; Revised 16 October 2016; Accepted 26 October 2016 \\ Academic Editor: Miguel Ferrando Bataller
}

Copyright (C) 2016 Yanfang Wang et al. This is an open access article distributed under the Creative Commons Attribution License, which permits unrestricted use, distribution, and reproduction in any medium, provided the original work is properly cited.

\begin{abstract}
A novel single- or dual-polarized ultra-wideband (UWB) patch antenna fed by coupled feeding mechanism is proposed. The singlepolarized antenna consists of a square ring patch and two $\Gamma$-shaped patches which are coupled to the radiating patch. The vertical portions of the $\Gamma$-shaped patches are connected to the microstrip lines which are printed on the bottom layer of the grounded FR4 substrate. To realize the differential feeding mechanism for enhancing the polarization purity, a tapered balun is employed to excite the antenna. Further to provide dual linear orthogonal polarizations, another pair of $\Gamma$-shaped patches is added in the singlepolarized UWB antenna. The dual-polarized UWB antenna prototype can achieve two orthogonal polarizations with an impedance bandwidth $\left(\left|S_{11}\right| \leq-10 \mathrm{~dB}\right)$ of $113 \%$ and isolation of over $25 \mathrm{~dB}$ across the entire frequency band.
\end{abstract}

\section{Introduction}

The development of UWB radars has received significant interests, particularly after the Federal Communications Commission (FCC) designated the frequency band from 3.1 to $10.6 \mathrm{GHz}$ for unlicensed use, as high-resolution sensing and imaging can be realized due to the large bandwidth. UWB radars can be applied for indoor and outdoor environments, including medical imaging for cancerous tissue detection, detection of human beings behind the wall and ground penetrating radar for mine detection $[1,2]$. Moreover, dualpolarized UWB antennas have substantial advantages in comparison with linearly polarized antennas, as the performance of the UWB radar can be improved by using an appropriate polarimetric method [3]. For radar applications, the proper antennas are required to achieve a wide impedance bandwidth with dual orthogonal polarization, high port-toport isolation, stable directional patterns, and compact size.

It is well known that patch antennas have been widely utilized in wireless communication systems and radar systems mainly due to their characteristics of low profile, easy fabrication, and low-cost. However, patch antennas can only operate in a limited frequency bandwidth which can not satisfy the FCC allocated UWB bandwidth. Consequently, various methods have been proposed for enhancing the bandwidth of dual-polarized patch antennas. The most used methods include optimizing the shapes of feeding probes [4$6]$, multiple radiating patches $[7,8]$, and aperture-coupled feeding mechanism [9-11]. The dual-polarized magnetoelectric dipole antenna in [6] is fed by four $\Gamma$-shaped probes and can achieve stable radiation characteristics across a wide frequency range. However, the relative operating bandwidths of the listed dual-polarized patch antennas [4-11] are less than $40 \%$. Recently, a popular method for designing a dualpolarized antenna is developed from the uniplanar monopole antenna which can work from 3 to $10 \mathrm{GHz}$. The planar dualpolarized antenna is obtained by employing two identical monopoles with one rotated by $90^{\circ}$ [12]. However, the antenna achieves doughnut-shaped patterns with omnidirectional radiation in the $\mathrm{H}$-plane and bidirectional radiation in the E-plane, thus leading to low antenna gain. In addition, the pattern is split at higher frequencies and unstable across the entire frequency band though the impedance bandwidth can meet UWB regulations. Another promising design is to employ two Vivaldi antennas with cross-shaped configuration to achieve a wide bandwidth [13], while it requires a large 


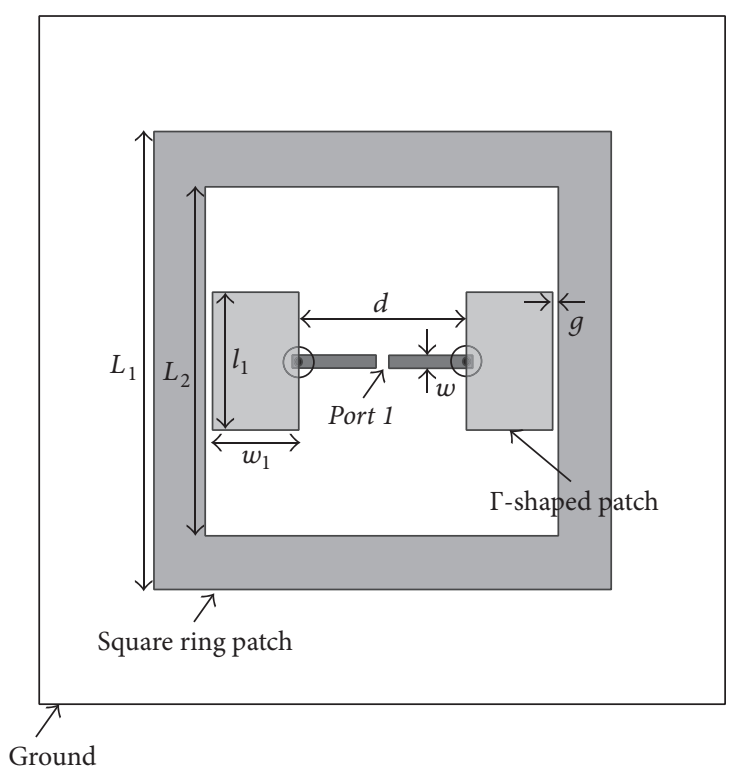

(a)

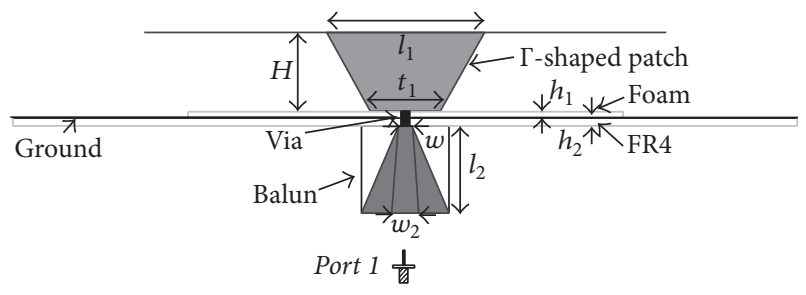

(b)

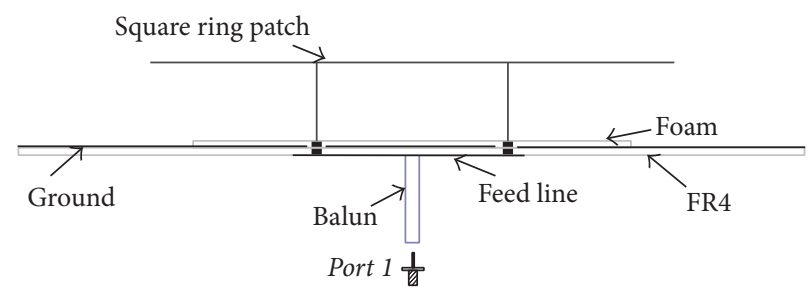

(c)

FIGURE 1: Geometry of the proposed single-polarized UWB patch antenna: (a) top view, (b) side view, and (c) front view. $L_{1}=65 \mathrm{~mm}, L_{2}=$ $45 \mathrm{~mm}, l_{1}=18 \mathrm{~mm}, w_{1}=11.3 \mathrm{~mm}, t_{1}=14 \mathrm{~mm}, d=22 \mathrm{~mm}, g=0.1 \mathrm{~mm}, w=1.5 \mathrm{~mm}, w_{2}=3.1 \mathrm{~mm}$, and $l_{2}=20 \mathrm{~mm}, H=9 \mathrm{~mm}, h_{1}=3.2 \mathrm{~mm}$, and $h_{2}=0.8 \mathrm{~mm}$.

space for accommodating the structure. A differential-fed slot-loaded patch antenna proposed in [14] can operate across the FCC UWB band with dual orthogonal polarizations and the impedance matching can be tuned by adjusting the tilt angle between the triangular feeders and the ground plane. Good impedance matching is obtained when the tilt angle is very small, thus leading to a large ground plane for supporting unidirectional radiation.

In this paper, a novel coupled-fed single- or dualpolarized patch antenna is proposed. The coupled feeds are applied for ensuring good impedance matching across the UWB frequency range. The proposed dual-polarized antenna achieves an impedance bandwidth of over $110 \%\left(\left|S_{11}\right| \leq\right.$ $-10 \mathrm{~dB}$ ) and port-to-port isolation of above $25 \mathrm{~dB}$ by adopting the differential feeding technique. The rest of the paper is organized as follows: the design of the single-polarized UWB patch antenna is demonstrated in Section 2. The parametric study of three key parameters has also been carried out in this section to understand the operating principles and choose the proper values of the dimensions. Section 3 presents the design of the dual-polarized UWB patch antenna, and both simulation and measurement results are given. A conclusion is drawn in Section 4.

\section{Single-Polarized UWB Antenna Design}

The configuration and geometry of the proposed singlepolarized UWB patch antenna are presented in Figure 1. As shown in Figure 1(a), the radiating square ring patch is coupled by two identical $\Gamma$-shaped patches which are symmetrically located with respect to the center of the structure. Each $\Gamma$-shaped patch is formed by a horizontal rectangular patch and a vertical isosceles trapezoidal patch. The square ring patch has an outer side with length of $L_{1}$ and an inner side with length of $L_{2}$. It is worth mentioning that the lowest operating frequency of the antenna is mainly determined by the dimensions of the radiating patch. Moreover, the impedance matching is tuned by adjusting the dimensions of the $\Gamma$-shaped patches and the gap between the inner sides of the radiating patch and top sides of the $\Gamma$-shaped patches. A pair of microstrip lines are fabricated on the backside of the grounded FR4 substrate with thickness of $h_{2}$ and connected to the bottom sides of the $\Gamma$-shaped patches by a conducting via. In addition, a piece of Rohacell foam with thickness of $h_{1}$ is attached on the ground to isolate and support the vertical parts of the $\Gamma$-shaped patches. Furthermore, a tapered balun [14] is applied to feed the antenna and play a role as differential feed to suppress cross-polarization and 


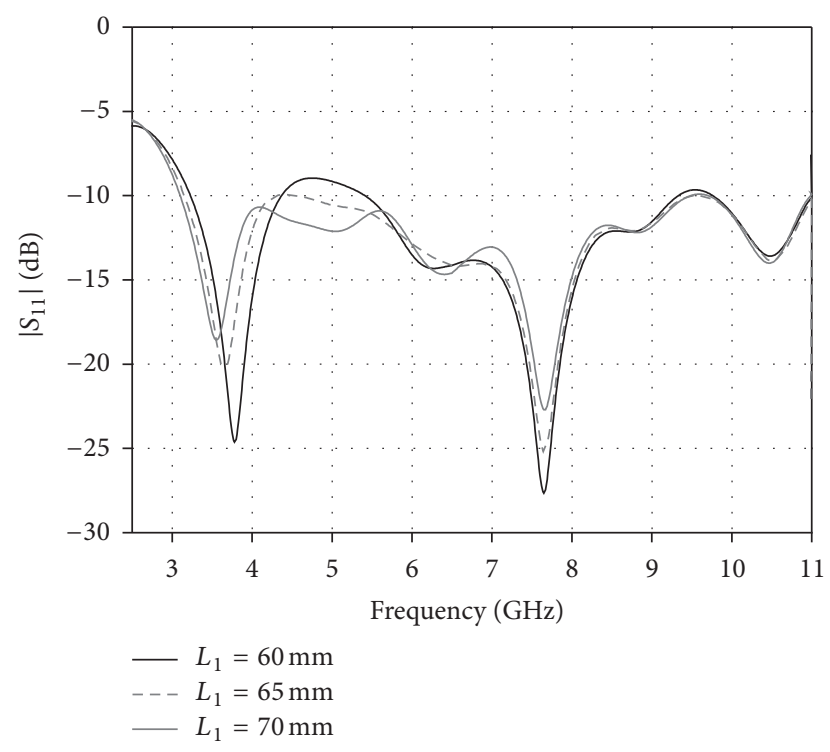

FIGURE 2: Effect of the outer side of the radiating patch $L_{1}$ on the reflection coefficient.

enhance port-to-port isolation. As illustrated in Figure 1(b), the balun is fabricated on a $1.6 \mathrm{~mm}$ thick FR4 substrate and perpendicular to the ground plane. The top sides of the balun are attached to the microstrip lines while the bottom sides are soldered to a $50 \Omega$ SMA connector. Figure 1(c) can also show that the feeding balun is mounted perpendicularly to the ground plane and parallel to the vertical parts of the $\Gamma$ shaped patches.

Since the dimensions of the square ring patch and $\Gamma$ shaped patches are the main factors in affecting the operating frequency range of the proposed antenna, the three parameters $L_{1}, g$, and $t_{1}$ are selected to implement the sensitivity study and understand the operating principles. The Ansoft HFSS 15.0 using Finite Element Method has been applied to implement the simulation and optimization of the proposed design. The effects of the three parameters on the reflection coefficient of the design are simulated and shown in Figures $2-4$. Figure 2 exhibits the influence of the outer side of the square ring patch $L_{1}$ on the reflection coefficient versus frequency. As expected, the proposed UWB antenna can work across the frequency range from around 3 to $11 \mathrm{GHz}$ and the lowest operating frequency is shifted from 3.25 to $3.08 \mathrm{GHz}$ when the length of the outer side increases. In addition, the impedance matching in the lower band is improved while kept unchanged in the upper band. In this work, the dimension of $L_{1}$ is chosen to cover the required lowest operating frequency. The effect of the gap between the inner side of the square ring patch and the top part of the $\Gamma$-shaped patch is shown in Figure 3. It is noted that the impedance matching in the lower band can be improved and the reflection coefficient is reduced as the gap decreases from 2.1 to $0.1 \mathrm{~mm}$. Also it is observed that when the gap is removed $(g=0 \mathrm{~mm})$, the reflection coefficient from 4 to $7 \mathrm{GHz}$ is further lowered while it becomes large abruptly in the band from 3 to $4 \mathrm{GHz}$. For achieving good impedance matching across the whole frequency band, the dimension of $g$ is selected as $0.1 \mathrm{~mm}$ when

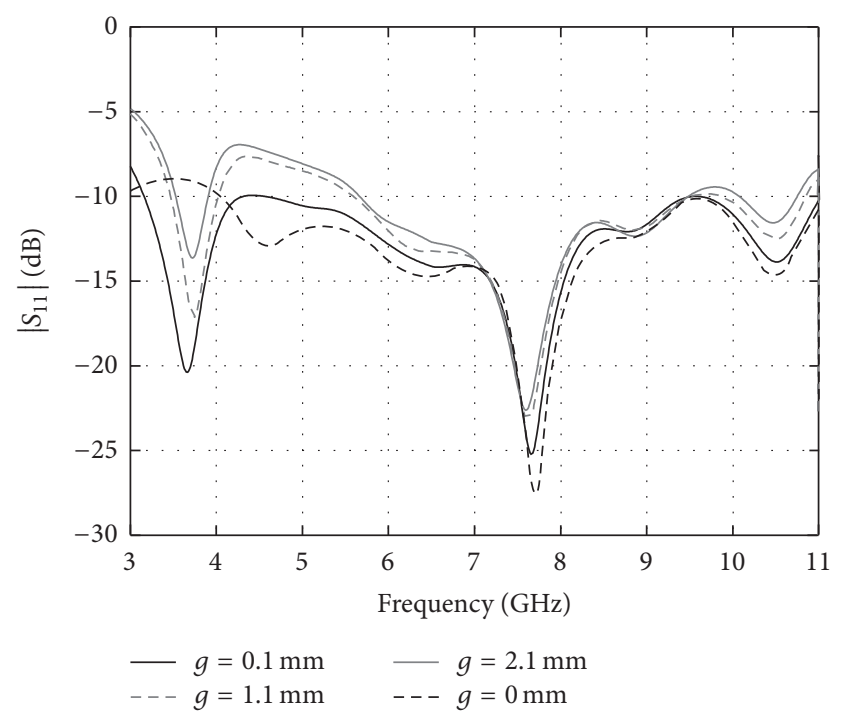

FigurE 3: Effect of the gap $g$ on the reflection coefficient.

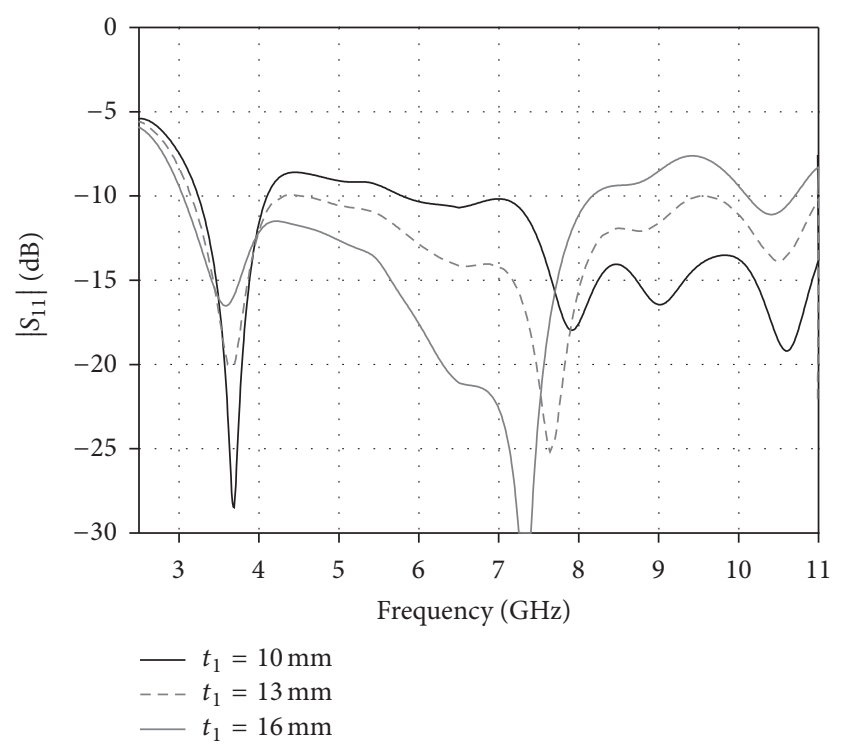

FIGURE 4: Effect of the bottom side of the $\Gamma$-shaped patch $t_{1}$ on the reflection coefficient.

considering the fabrication tolerance. Figure 4 presents the effect of the bottom side of the $\Gamma$-shaped patch $t_{1}$ on the reflection coefficient. It is observed that it can change the reflection coefficient in both lower and upper bands. The reflection coefficient decreases in the lower band and increases in the upper band when $t_{1}$ changes from 10 to $16 \mathrm{~mm}$.

\section{Dual-Polarized UWB Antenna Design}

Based on the design and analysis of the single-polarized UWB patch antenna in previous section, a compact UWB antenna with dual orthogonal polarizations is obtained by adding another pair of $\Gamma$-shaped patches. As illustrated in Figure 5 , the four $\Gamma$-shaped patches are symmetrical with respect to the center of the dual-polarized UWB antenna and 


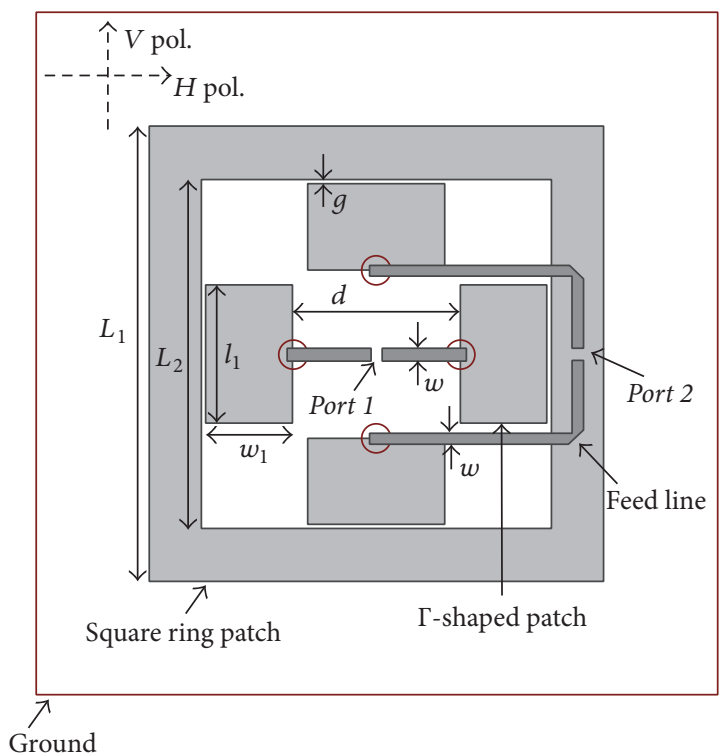

(a)

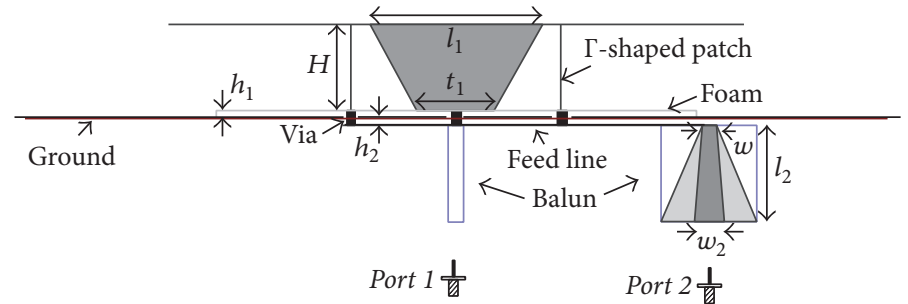

(b)

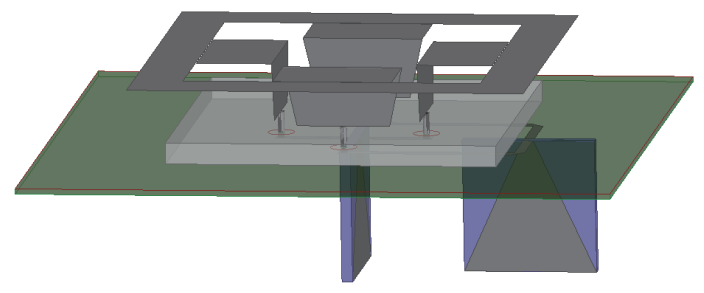

(c)

Figure 5: Construction of the proposed dual-polarized UWB antenna: (a) top view, (b) side view, and (c) $3 \mathrm{D}$ view. $L_{1}=65 \mathrm{~mm}, L_{2}=45 \mathrm{~mm}$, $l_{1}=18 \mathrm{~mm}, w_{1}=11.3 \mathrm{~mm}, t_{1}=14 \mathrm{~mm}, d=22 \mathrm{~mm}, g=0.1 \mathrm{~mm}, w=1.5 \mathrm{~mm}, w_{2}=3.1 \mathrm{~mm}$, and $l_{2}=20 \mathrm{~mm}, H=9 \mathrm{~mm}, h_{1}=3.2 \mathrm{~mm}$, and $h_{2}=$ $0.8 \mathrm{~mm}$.

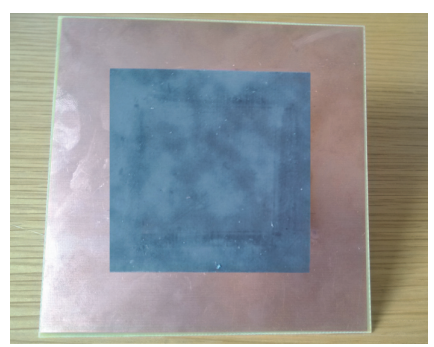

(a) Top view

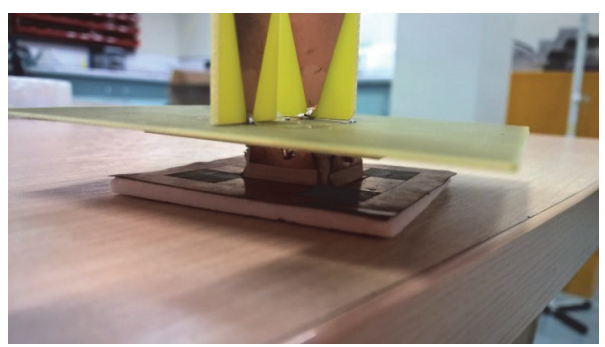

(b) Side view

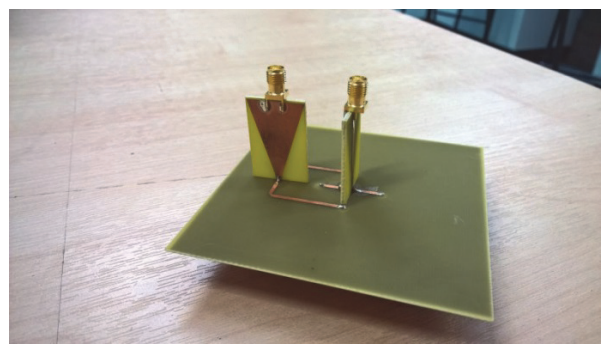

(c) Bottom view

FIGURE 6: Photo of the fabricated prototype.

coupled to the square ring patch. The bottom sides of the $\Gamma$ shaped patches are soldered to the four microstrip lines by vias through via holes in the conducting ground plane. As observed, Port 1 is excited for horizontal polarization while Port 2 is for vertical polarization. The optimized values of the dimensions for the proposed design are also presented in Figure 5. Figure 6 presents the photo of the fabricated prototype. The square ring patch and the four horizontal parts of the $\Gamma$-shaped patches are fabricated on a single $0.127 \mathrm{~mm}$ thick Duroid 5880 substrate, while the vertical parts of the
$\Gamma$-shaped patches are fabricated by using four independent Duroid 5880 substrates. Then, the top sides of vertical parts are attached to the horizontal parts of the $\Gamma$-shaped patches using copper tape. Both the feeding lines on the back side of the ground plane and baluns are fabricated by employing the FR4 substrates, respectively. The bottom of the vertical parts are connected and soldered to the feeding lines on the back of the ground plane with conducting posts. To avoid the touch between the $\Gamma$-shaped patches and the ground plane, a piece of Rohacell foam is inserted between them. Finally, 


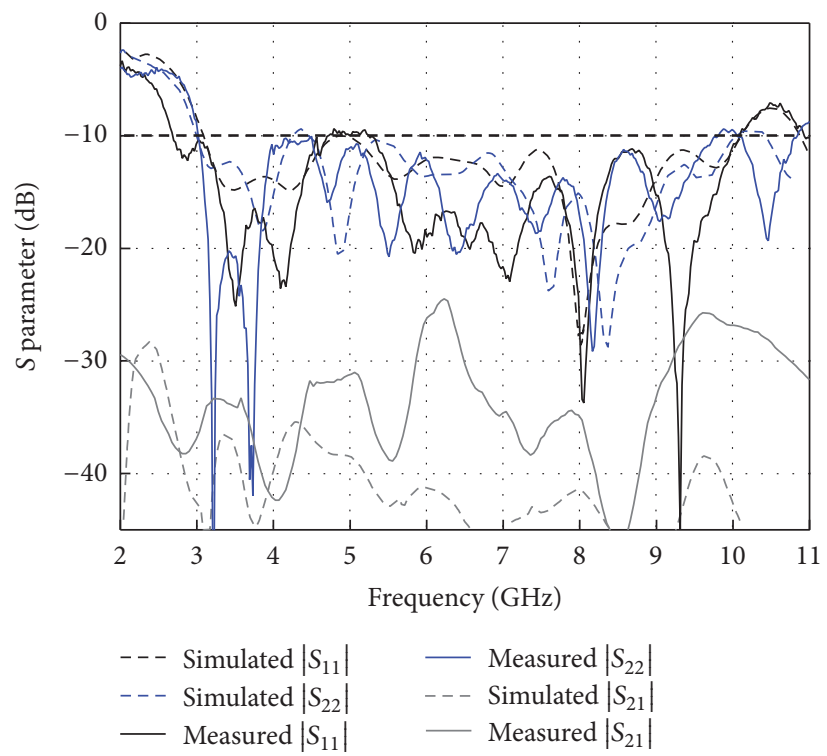

FIGURE 7: Simulated and measured results of $S$-parameters for the dual-polarized UWB antenna.

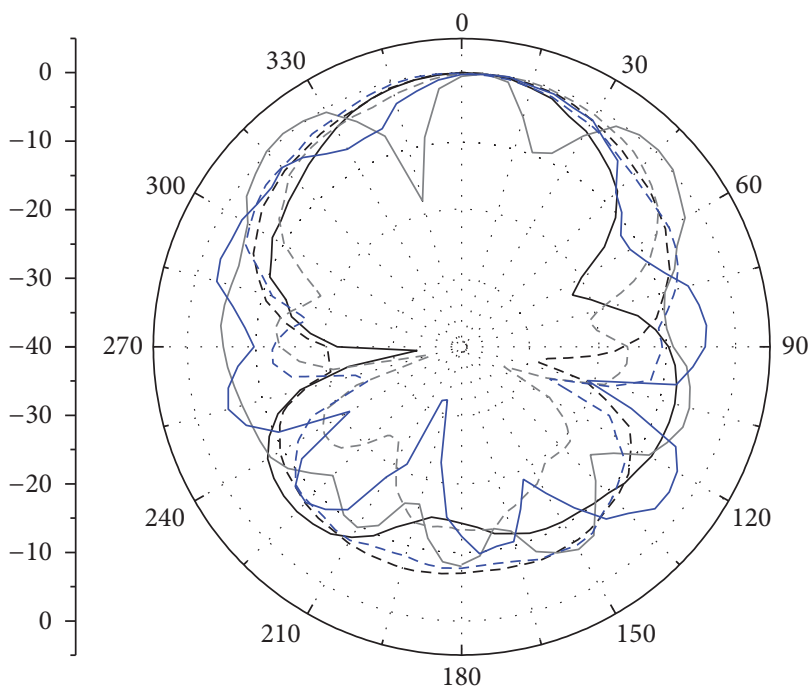

$\begin{array}{ll}\text { E-co. }(3 \mathrm{GHz}) & --H \text {-co. }(6 \mathrm{GHz}) \\ ---H \text {-co. }(3 \mathrm{GHz}) & -E \text {-co. }(9 \mathrm{GHz}) \\ \text { - } & \text {-co. }(6 \mathrm{GHz})\end{array}$

(a)

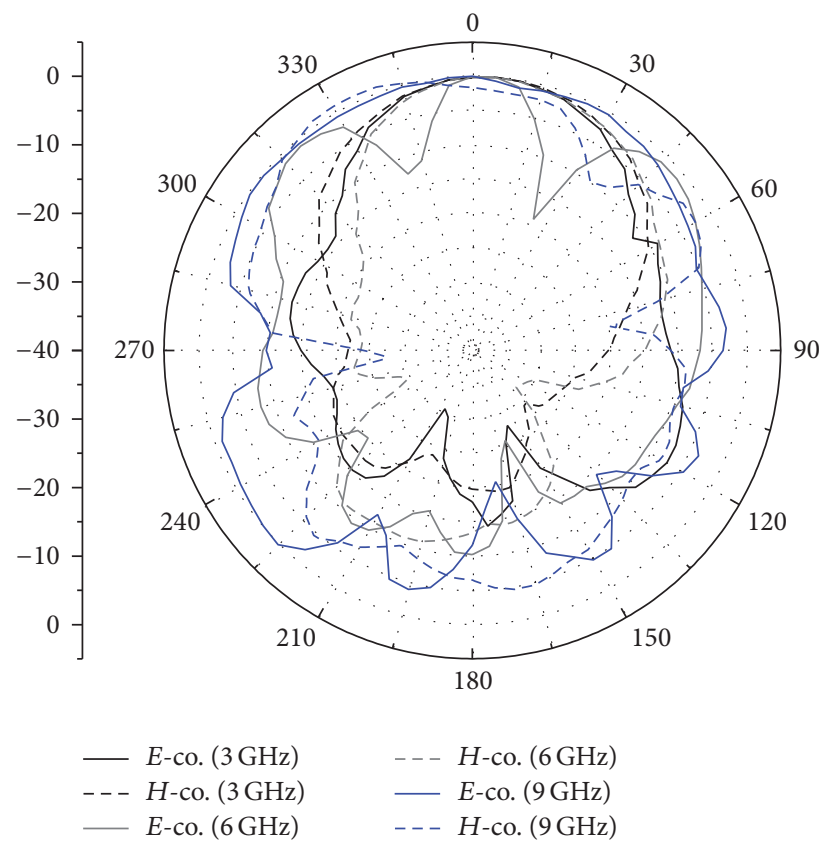

(b)

FIgURE 8: Measured copolarized radiation patterns at three different frequencies: (a) Port 1 is excited and Port 2 is terminated with a $50 \Omega$ load. (b) Port 2 is excited and Port 1 is terminated with a $50 \Omega$ load.

the baluns are mounted to center of the feeding lines and perpendicularly to the ground plane.

A prototype has been fabricated and measured to validate the proposed design principle. The simulated and measured $S$-parameters of the proposed antenna are presented in Figure 7. The measured results confirm that Port 1 has over $115 \%$ impedance bandwidth (from 2.7 to $10.1 \mathrm{GHz}$ ) for $\left|S_{11}\right| \leq$ $-10 \mathrm{~dB}$ while Port 2 achieves an impedance bandwidth of $113 \%$ (from 3 to $10.8 \mathrm{GHz}$ ). It is also noted that the measured mutual coupling between the two ports is less than $-25 \mathrm{~dB}$ across the entire frequency range and the simulation is less than $-30 \mathrm{~dB}$. Ideally, the top sides of the feeding baluns should be precisely attached to ends of the feeding lines on the ground plane. However, the fabrication may lead to some tolerances which will deteriorate the performance of the baluns. This is coherent with the phenomenon that the measured isolation is larger than the simulation, as shown in Figure 7. The measured copolarized patterns at three different frequencies in both principal planes are illustrated in Figure 8 . As noticed, both polarizations exhibit similar radiation 


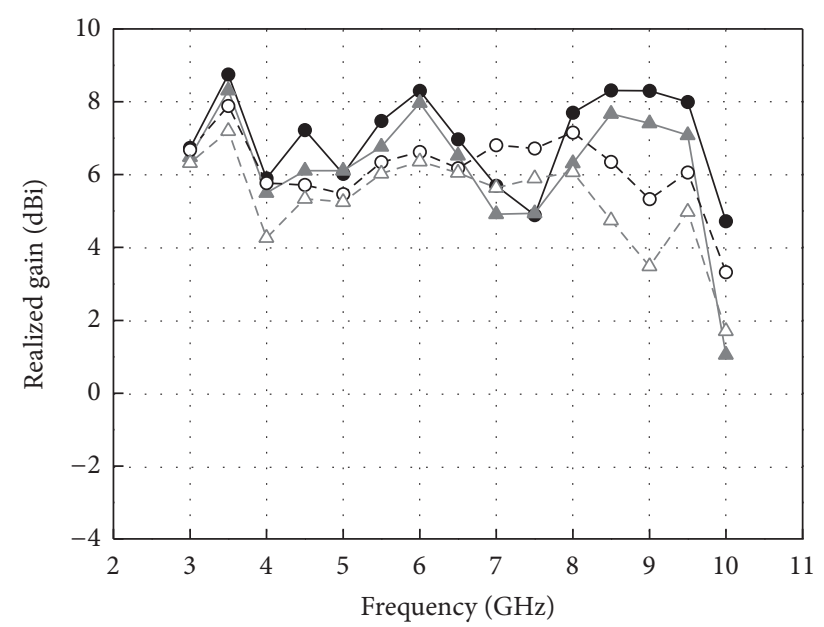

$\begin{array}{ll}- \text { Port } 1 \text { (simulation) } & -\mathrm{O}-\text { Port } 1 \text { (measurement) } \\ - \text { Port } 2 \text { (simulation) } & -\triangle \text { - Port } 2 \text { (measurement) }\end{array}$

FIGURE 9: Simulated and measured realized gain versus frequency.

characteristics. Relatively consistent unidirectional patterns over the operating frequency band have been obtained. The Front-to-Back Ratio (FBR) is around 15,10 , and $8 \mathrm{~dB}$ at 3, 6 , and $9 \mathrm{GHz}$, respectively. The decrement of FBR against frequency is caused by two factors. One is that the electrical length of the feeding balun is comparable to the wavelength at higher frequency; thus it may cause backward radiation. The other one is that the vertical parts of the $\Gamma$-shaped patches may support unwanted radiation adding to the main radiation of the antenna. The simulated and measured realized gains of the proposed antenna are shown in Figure 9. The simulation implicates that the realized gain at Port 1 changes from 6.73 to $4.72 \mathrm{dBi}$ and from 6.48 to $1.05 \mathrm{dBi}$ at Port 2 versus frequency, respectively, while the measurement shows that the realized gain at Port 1 varies from 6.68 to $3.32 \mathrm{dBi}$ and from 6.32 to $1.7 \mathrm{dBi}$ at Port 2 from 3 to $10 \mathrm{GHz}$, respectively. The electrical length between the vertical portions of the $\Gamma$ shaped patches varies versus frequency, thus inducing significant side lobes at high frequencies and gain drop at $10 \mathrm{GHz}$.

\section{Conclusions}

The investigation and design of single- or dual-polarized UWB patch antennas have been shown in this paper. The proposed dual-polarized UWB antenna achieves a wide frequency band over $3-10 \mathrm{GHz}$ with dual polarizations and the port-to-port isolation is above $25 \mathrm{~dB}$.

\section{Competing Interests}

The authors declare that they have no competing interests.

\section{Acknowledgments}

The project is supported by the funding from the National Natural Science Foundation of China (Grant no. 61502145), the Fundamental Research Funds for the Central Universities of China (2014B13114), Surrey Space Centre, University of Surrey, UK, Department of Computing, University of Surrey,
UK, and School of Engineering and Digital Arts, University of Kent, UK. Some measurements were carried out at the anechoic chamber of the Antenna Group at University of Bradford, UK. The authors would like to thank Professor Raed A. Abd-Alhameed and Dr. Chan See for their help during the measurement.

\section{References}

[1] T. Sugitani, S. Kubota, A. Toya, X. Xiao, and T. Kikkawa, "A compact $4 \times 4$ planar UWB antenna array for 3 -D breast cancer detection," IEEE Antennas and Wireless Propagation Letters, vol. 12, pp. 733-736, 2013.

[2] F. Fioranelli, S. Salous, I. Ndip, and X. Raimundo, "Throughthe-wall detection with gated FMCW signals using optimized patch-like and Vivaldi antennas," IEEE Transactions on Antennas and Propagation, vol. 63, no. 3, pp. 1106-1117, 2015.

[3] A. Elsherbini, J. Wu, and K. Sarabandi, "Dual polarized wideband directional coupled sectorial loop antennas for radar and mobile base-station applications," IEEE Transactions on Antennas and Propagation, vol. 63, no. 4, pp. 1505-1513, 2015.

[4] J.-J. Xie, X.-S. Ren, Y.-Z. Yin, and J. Ren, "Dual-polarised patch antenna with wide bandwidth using electromagnetic feeds," Electronics Letters, vol. 48, no. 22, pp. 1385-1386, 2012.

[5] J. Zhang, X. Q. Lin, L. Y. Nie, J. W. Yu, and Y. Fan, "Wideband dual-polarization patch antenna array with parallel strip line balun feeding," IEEE Antennas and Wireless Propagation Letters, vol. 15, pp. 1499-1501, 2016.

[6] L. Siu, H. Wong, and K.-M. Luk, "A dual-polarized magnetoelectric dipole with dielectric loading," IEEE Transactions on Antennas and Propagation, vol. 57, no. 3, pp. 616-623, 2009.

[7] J. Huang, Z. Hussein, and A. Petros, "A wide-band dualpolarized VHF microstrip antenna for global /sup s/ensing of sea ice thickness," in Proceedings of the IEEE Antennas and Propagation Society International Symposium, vol. 2, pp. 684687, Washington, DC, USA, July 2005.

[8] J. L. Vazquez-Roy, V. Krozer, and J. Dall, "Wideband dualpolarization microstrip patch antenna array for airborne ice sounder," IEEE Antennas and Propagation Magazine, vol. 54, no. 4, pp. 98-107, 2012.

[9] S. C. Gao, L. W. Li, P. Gardner, and P. S. Hall, "Wideband dualpolarised microstrip patch antenna," Electronics Letters, vol. 37, no. 20, pp. 1213-1214, 2001.

[10] Q. Fang, L. Song, M. Jin, Y. Han, and X. Qiao, "Dual polarised aperture-coupled patch antenna using asymmetrical feed," IET Microwaves, Antennas and Propagation, vol. 9, no. 13, pp. 13991406, 2015.

[11] M. Barba, "A high-isolation, wideband and dual-linear polarization patch antenna," IEEE Transactions on Antennas and Propagation, vol. 56, no. 5, pp. 1472-1476, 2008.

[12] R. V. S. S. Krishna and R. Kumar, "A dual-polarized square-ring slot antenna for UWB, imaging, and radar applications," IEEE Antennas and Wireless Propagation Letters, vol. 15, pp. 195-198, 2016.

[13] M. Sonkki, D. Sánchez-Escuderos, V. Hovinen, E. T. Salonen, and M. Ferrando-Bataller, "Wideband dual-polarized crossshaped Vivaldi antenna," IEEE Transactions on Antennas and Propagation, vol. 63, no. 6, pp. 2813-2819, 2015.

[14] K. Zhang, F. Zhu, and S. Gao, "Differential-fed ultra-wideband slot-loaded patch antenna with dual orthogonal polarisation," Electronics Letters, vol. 49, no. 25, pp. 1591-1593, 2013. 


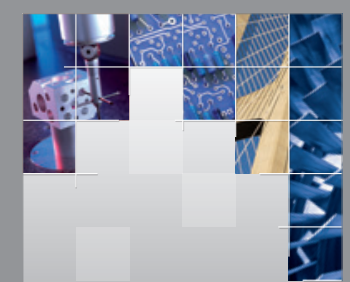

\section{Enfincering}
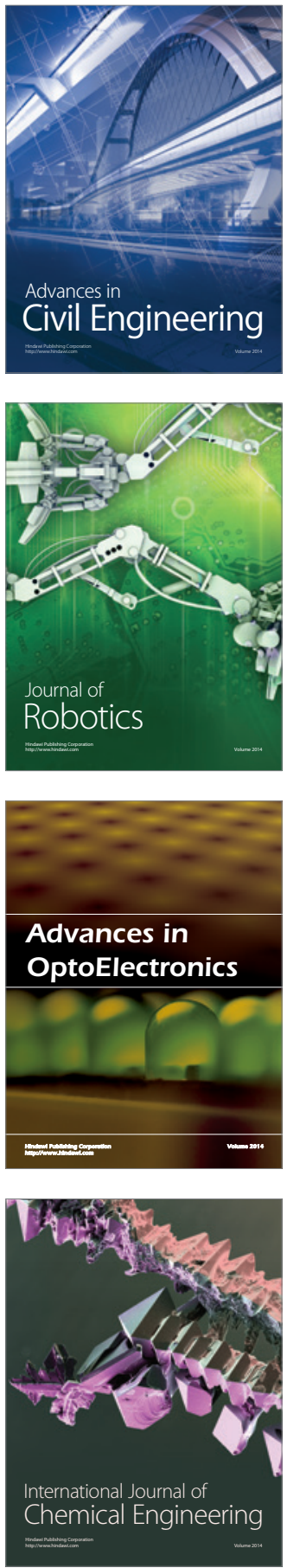

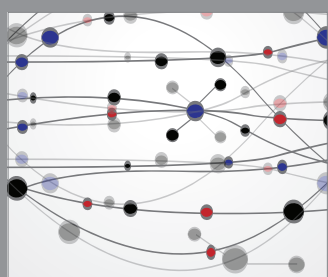

The Scientific World Journal

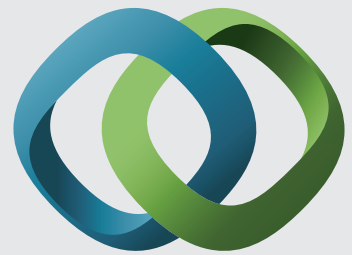

\section{Hindawi}

Submit your manuscripts at

http://www.hindawi.com
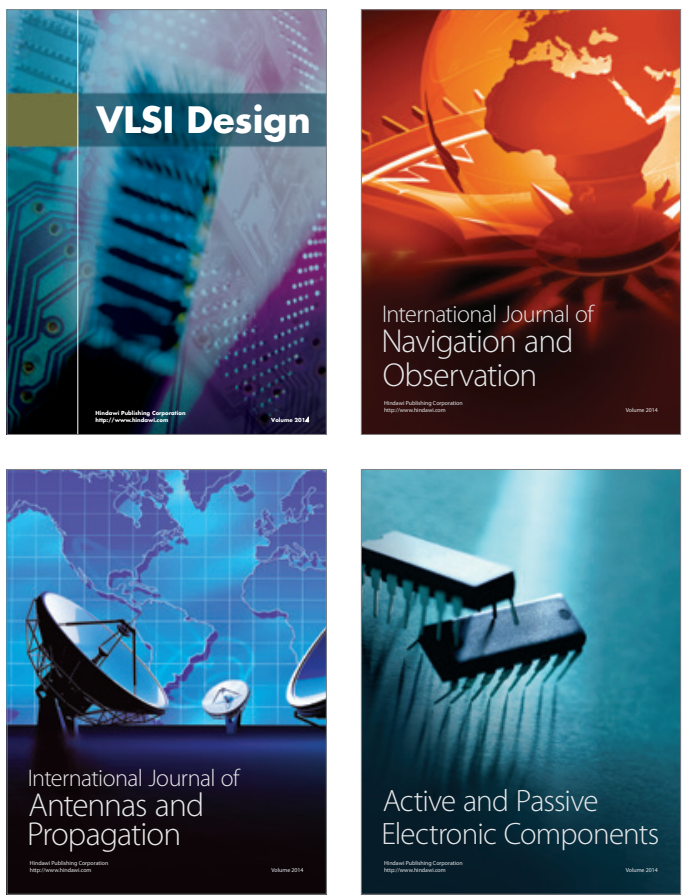
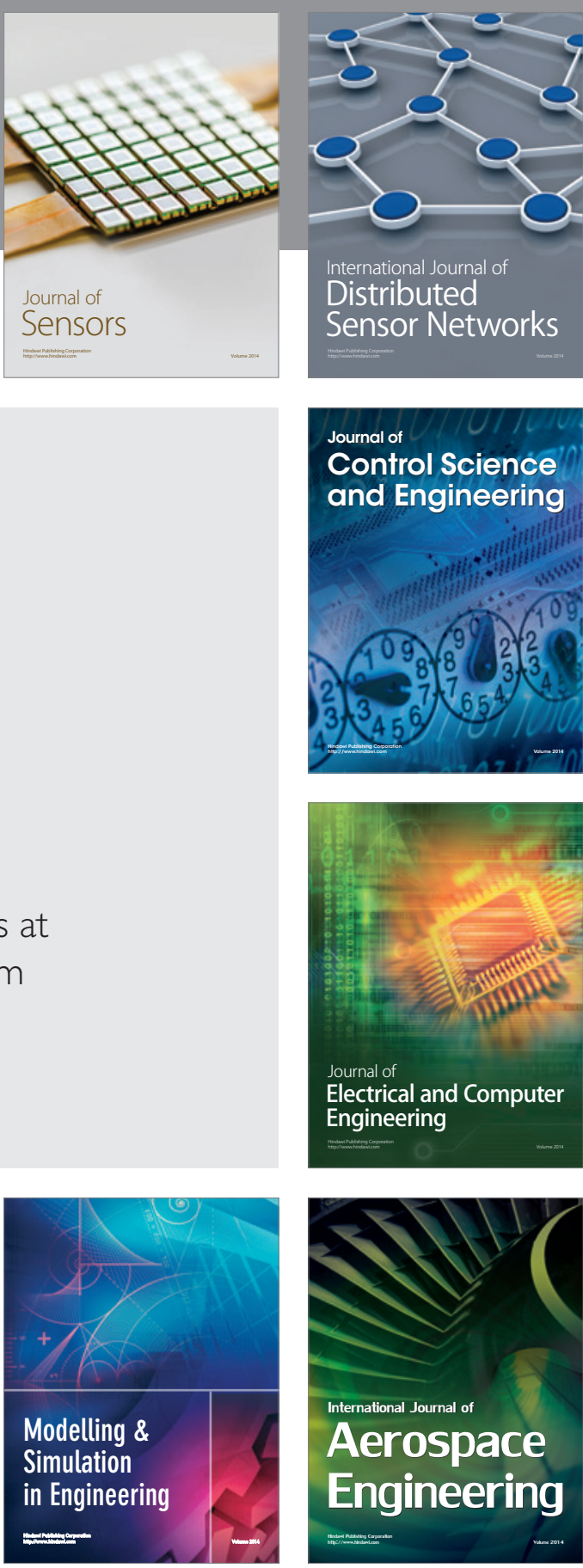

International Journal of

Distributed

Sensor Networks

Journal of

Control Science

and Engineering
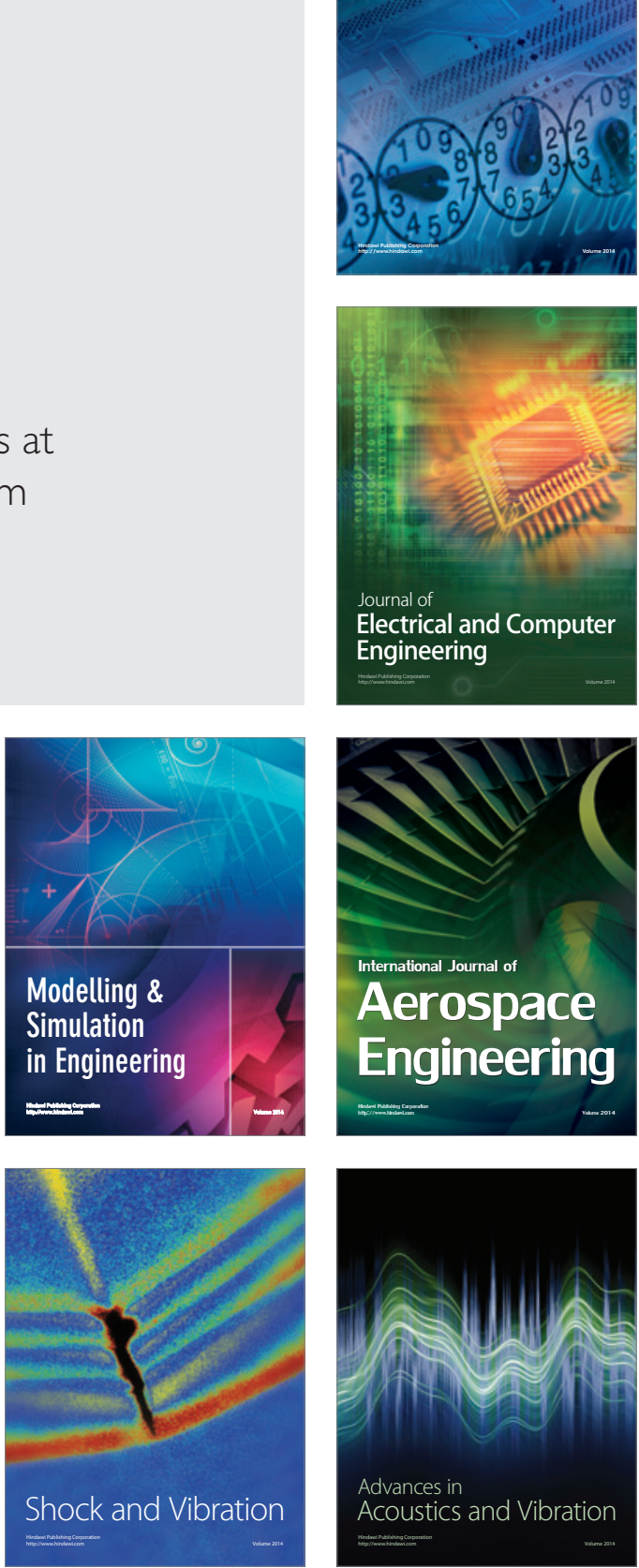